Research paper

\title{
Influence of socioeconomic deprivation on interventions and outcomes for patients admitted with COVID-19 to critical care units in Scotland: A national cohort study
}

\author{
Nazir I Lone ${ }^{1,2, *}$, Joanne McPeake ${ }^{3}$, Neil I Stewart ${ }^{4}$, Michael C Blayney ${ }^{1,5}$, Robert Chan Seem ${ }^{5}$, \\ Lorraine Donaldson ${ }^{5}$, Elaine Glass ${ }^{6}$, Catriona Haddow ${ }^{5}$, Ros Hall ${ }^{5}$, Caroline Martin ${ }^{5}$, \\ Martin Paton ${ }^{5}$, Alison Smith-Palmer ${ }^{5}$, Callum T Kaye ${ }^{7, * *}$, Kathryn Puxty ${ }^{3, *, *}$, on behalf of the \\ Scottish Intensive Care Society Audit Group \\ ${ }^{1}$ Usher Institute, University of Edinburgh, UK \\ ${ }^{2}$ NHS Lothian, UK \\ ${ }^{3}$ NHS Greater Glasgow and Clyde, UK \\ ${ }^{4}$ NHS Forth Valley, UK \\ ${ }^{5}$ Public Health Scotland, UK \\ ${ }^{6}$ NHS National Services Scotland, UK \\ ${ }^{7}$ NHS Grampian, UK
}

\section{A R T I C L E I N F O}

\section{Article History:}

Received 7 October 2020

Revised 15 November 2020

Accepted 16 November 2020

Available online 19 November 2020

\section{Keywords:}

COVID-19

Intensive care

Social deprivation

Mortality

\begin{abstract}
A B S T R A C T
Background: Coronavirus disease 2019 (COVID-19) can lead to significant respiratory failure with between $14 \%$ and $18 \%$ of hospitalised patients requiring critical care admission. This study describes the impact of socioeconomic deprivation on 30-day survival following critical care admission for COVID-19, and the impact of the COVID-19 pandemic on critical care capacity in Scotland.

Methods: This cohort study used linked national hospital records including ICU, virology testing and national death records to identify and describe patients with COVID-19 admitted to critical care units in Scotland. Multivariable logistic regression was used to assess the impact of deprivation on 30-day mortality. Critical care capacity was described by reporting the percentage of baseline ICU bed utilisation required.

Findings: There were 735 patients with COVID-19 admitted to critical care units across Scotland from 1/3/ 2020 to 20/6/2020. There was a higher proportion of patients from more deprived areas, with 183 admissions (24.9\%) from the most deprived quintile and 100 (13.6\%) from the least deprived quintile. Overall, 30-day mortality was $34.8 \%$. After adjusting for age, sex and ethnicity, mortality was significantly higher in patients from the most deprived quintile (OR 1.97, 95\%CI 1.13, 3.41, p=0.016). ICUs serving populations with higher levels of deprivation spent a greater amount of time over their baseline ICU bed capacity.

Interpretation: Patients with COVID-19 living in areas with greatest socioeconomic deprivation had a higher frequency of critical care admission and a higher adjusted 30-day mortality. ICUs in health boards with higher levels of socioeconomic deprivation had both higher peak occupancy and longer duration of occupancy over normal maximum capacity.

Funding: None.
\end{abstract}

(c) 2020 The Authors. Published by Elsevier Ltd. This is an open access article under the CC BY-NC-ND license (http://creativecommons.org/licenses/by-nc-nd/4.0/)

\section{Introduction}

The first confirmed case of coronavirus disease 2019 (COVID-19) in the UK was reported on $31^{\text {st }}$ January 2020 [1]. Since then, the UK has seen over 1,000,000 cases of the disease, resulting in more than

\footnotetext{
* Corresponding author.

E-mail address: nazir.lone@ed.ac.uk (N.I. Lone).

* CK and KP contributed equally to this paper.
}

48,000 deaths [2]. Among patients in Germany and the USA who require acute hospitalisation due to COVID-19 infection, between $14 \%$ and $18 \%$ of them will require admission to a critical care unit, with variable mortality reported for those patients requiring invasive ventilation $[3,4]$.

Several risk factors for admission to critical care have been identified including the presence of comorbidities such as hypertension and obesity, as well as demographic features such as increasing age and male gender $[5,6]$. Other studies have focussed on biological risk 


\section{Research in context}

\section{Evidence before this study}

Several risk factors for admission to critical care have been identified including the presence of comorbidities such as hypertension and obesity, as well as demographic features such as increasing age and male gender. People residing in an area of socioeconomic deprivation and Black, Asian and minority ethnic (BAME) groups also appear at greater risk of critical illness and mortality. We searched PubMed, medRxiv and Medline for studies relating to socioeconomic deprivation and critical care outcome and critical care capacity in relation to the COVID-19 pandemic using search terms "COVID-19", "SARS-CoV-2", "Critical Care" and "Socioeconomic Status" and synonyms.

\section{Added value of this study}

We were able to analyse a complete national cohort study of patients with COVID-19 admitted to critical care units. We found that those living in areas in the most socioeconomically deprived quintile of Scotland had a higher chance of critical care admission and a higher adjusted 30-day mortality. Uniquely, we were able to evaluate the impact on service provision in hospitals across different socioeconomic catchment areas and the change required in critical care capacity to meet demand. This demonstrated that health boards with higher levels of socioeconomic deprivation had both higher peak critical care occupancy and longer duration of occupancy over normal maximum capacity.

\section{Implications of all the available evidence}

Our study supports the existing literature that has demonstrated an association between socioeconomic status and poorer outcomes for patients with COVID-19. Given that critical care units serving socioeconomically deprived areas experienced a higher peak of demand for critical care and for a more prolonged period of time, a more targeted approach to additional resource should be considered in future pandemic waves.

factors for critical care outcomes [7]. People residing in an area of socioeconomic deprivation and Black, Asian and minority ethnic (BAME) groups also appear at greater risk of critical illness and mortality $[6,8,9]$. However, less is known about service provision in relation to critical care service organisation and how critical care capacity changed during the COVID-19 pandemic.

This study describes the demographics, baseline characteristics, critical care unit and 30-day outcomes from a complete national dataset of critical care admissions for COVID-19. In addition, it evaluates the association of residing in an area of socioeconomic deprivation with 30-day mortality following admission to critical care with COVID-19. Uniquely, the impact on service provision in hospitals across different socioeconomic catchment areas and the change required in critical care capacity is also evaluated.

\section{Methods}

\subsection{Study setting and databases}

Data sources were linked using the Community Health Index (CHI) number, a unique identifier used in health systems in Scotland, and included the following databases held within Public Health Scotland: Scottish Morbidity Record 01 (SMR01), which captures acute hospital activity; Electronic Communication of Surveillance in Scotland (ECOSS) database, which captures all virology testing in Scotland; National Records of Scotland death records; and the Scottish Intensive Care Society Audit Group (SICSAG) database. The SICSAG database captures all adult general intensive care (ICU) and high dependency unit (HDU) activity within Scotland and is subject to regular validation assessments [10].

\subsection{Participants}

We used a cohort study design. The cohort comprised Scottish residents aged $\geq 16$ years admitted to general ICUs and HDUs in Scotland from $01 / 03 / 2020$ to $20 / 06 / 2020$ with a positive polymerase chain reaction test for nucleic acid for SARS-CoV-2 before or during critical care admission. For patients with multiple admissions, only the first admission was included. For analyses relating to ICU capacity, first and subsequent admissions for patients regardless of COVID19 status were included. Due to reconfiguration of services impacting on patient flow (e.g. admission to assessment beds awaiting test then transfer to a different unit within the same hospital) there were multiple records for a single continuous episode of care. These records were merged to create continuous critical care stays.

\subsection{Variables}

Outcomes: The primary outcome was 30-day mortality after critical care admission. Other reported outcomes included vital status at critical care discharge, length of critical care stay, and type/duration of organ support during critical care stay. The start of follow up for each patient was date of critical care admission and end of follow-up was 30 days after admission for survival analyses. Critical care unit outcomes were available for those with complete data who had been discharged or died on or before 31/08/2020.

Exposure: The primary exposure was socioeconomic deprivation, defined using quintiles of the Scottish Index of Multiple Deprivation (SIMD Version 2020) [11]. This is an area-based ranking index based on postcode of residence. It is a weighted score combining 7 domains (income, employment, health, education, skills and training, housing, geographic access and crime). SIMD identifies small areas of concentrated socioeconomic deprivation and therefore only identifies individuals who reside in areas of socioeconomic deprivation, rather than individual socioeconomic position. Each small area is known as a datazone and has a median population of around 760 .

Other variables: Demographic variables were age, sex and ethnicity. Ethnicity was derived from categories of the Scottish Census 2011 [12] aggregated due to low frequencies. For example, the category "White" includes "English", "Welsh", “Northern Irish", "British", "Gypsy/Traveller" and "Polish." Previous health status comprised the number of emergency acute hospital admissions in the year before admission and comorbidities. Comorbidities were derived from the Charlson list of comorbidities as identified on prior hospital discharge records in the SMR01 database, combined with SICSAG defined severe comorbidities $[13,14]$ These were presented as a count of comorbidities and as individual comorbidities, with small frequencies aggregated due to disclosure control. Acute illness variables comprised the Acute Physiology Score (APS) of the APACHE II model, $\mathrm{PaO2}$ :FiO2 (PF) ratio, time from hospital admission to ICU admission, number of organ systems supported on the day of critical care admission (defined as renal support, respiratory support and cardiovascular support).

\subsection{Statistical analysis}

Data were analysed using R Version 3.6.1 [15]. No sample size calculation was performed as this was fixed by the number of admissions. Missing data for ethnicity and APS variables were grouped in 
an indicator variable. APS is not a mandatory data field for HDU patients. Linearity assumption was evaluated for age and APS (Figure S1) and age was entered as a linear term. A complete cases analysis was performed for all other variables in analyses.

Univariable associations: The univariable association of socioeconomic deprivation with the outcome were assessed by logistic regression model and reporting the odds ratio with 95\% confidence interval $(95 \% \mathrm{CI})$. We used logistic regression rather than survival models because follow-up was complete at 30 days for all patients. Kaplan-Meier plots were presented for overall survival, and stratified by socioeconomic deprivation, age and ventilation status.

Multivariable associations: We assessed the association with the outcome using logistic regression using a sequential approach. Age, sex and ethnicity were included in the base model as potential confounders. Pre-existing health status (comorbidities, previous number of emergency admissions) and severity of illness on admission (APS) could be potential mediators or confounders and were added to a second model.

Daily admissions to critical care were stratified by socioeconomic deprivation. Organ support activity was presented on a daily basis derived from Augmented Care Period (ACP) data [10]. ACP is used to assess the resources used in treating critically ill patients in order to categorise care requirements into different levels of care. For each day of admission, organ support activity and levels of care are recorded in the database. Levels of care are derived from number and type of organ support, with level 3 care being the highest including all patients receiving invasive mechanical ventilation [9]. Organ support activity was presented for the whole cohort stratified by levels of care and type of organ support. Capacity levels were analysed by allocating a level of care for each day for each patient and reporting this as a percentage of baseline funded level 3 capacity by units [10]. Health boards were grouped into three groups based on the proportion of total datazone areas ranked in the most socioeconomically deprived $20 \%$ datazones in Scotland: high (29.9\% of combined datazones fall within the most socioeconomically deprived $20 \%$ of datazones in Scotland) (NHS Greater Glasgow and Clyde, NHS Ayrshire and Arran, NHS Lanarkshire, NHS Fife); medium 14.1\% (NHS Tayside, NHS Forth Valley, NHS Lothian); and low 7.0\% (NHS Dumfries and Galloway, NHS Highland, NHS Borders, NHS Grampian, NHS island boards) [11].

Subgroup analyses: We repeated analyses for those who were invasively mechanically ventilated during their critical care stay as this group is less subject to variation in health service organisation.

\subsection{Approvals}

Linkage to additional datasets was approved for work undertaken by SICSAG within Public Health Scotland following scrutiny by the Public Benefit and Privacy Panel for Health and Social Care (19200093). Access and use of the data for the purpose of this work were approved following a Public Health Scotland information governance review of linking internal datasets. Only analysts working in Public Health Scotland had access to the linked patient data which could only be accessed via an NHS secure network.

\subsection{Role of the funding source}

The funder had no role in the study design; in the collection, analysis and interpretation of the data; in the writing of the report; and in the decision to submit the paper for publication.

\section{Results}

From 1 March to 20 June 2020 a total of 735 patients with laboratory confirmed COVID-19 disease were admitted to critical care units across Scotland. The first admission occurred on 4 March and the highest frequency of admissions occurred between 29 March and 7 April (Figure S2).

Baseline demographic and clinical characteristics, stratified by socioeconomic deprivation, are presented in Table 1. Median age of patients admitted to critical care units was 61 years (IQR 53,68) and was similar across socioeconomic deprivation quintiles. Males accounted for $70.1 \%$ of patients. $91.1 \%$ of those without missing ethnicity data identified as belonging to white ethnic groups (representing 52.6\% (387/735) of all patients . There was a higher proportion of patients admitted to critical care from more socioeconomically deprived areas, with 183 admissions (24.9\%) from the most deprived quintile and 100 (13.6\%) from the least deprived quintile (Fig. 1). Baseline characteristics for the 47 patients (6.4\%) who did not have SIMD recorded are presented in Table S1. Those with missing data were of similar age, had higher levels of comorbidity and received more advanced respiratory support compared to those without missing data.

Over one third of patients had at least one comorbidity. The most commonly recorded comorbidities were Respiratory Disease (12.0\%) and Diabetes Mellitus (11.6\%). There was a higher prevalence of comorbidity with increasing socioeconomic deprivation, with $42.1 \%$ of patients residing in the most deprived quintile having one or more comorbidities compared to $22.0 \%$ of patients from the least deprived quintile. One in eight patients had been admitted to hospital as an emergency in the preceding year, demonstrating a similar social gradient (most deprived vs least deprived SIMD quintile $14.2 \%$ vs $8.0 \%$ ).

Support of one or more organ systems was required by $68.7 \%$ of patients on admission to critical care. On the day of admission invasive respiratory support was received by $44.9 \%$ of patients, cardiovascular support by $32.5 \%$ and $1.4 \%$ received renal replacement therapy (RRT). This was similar across all SIMD quintiles.

Baseline characteristics were further stratified by receipt of invasive ventilation (Table S2). 421 patients (57\%) received invasive ventilation during their critical care stay. In this group, comorbidities were less prevalent compared to those who did not receive invasive ventilation (27.0\% vs $43.6 \%$ ).

\subsection{Interventions and outcomes}

Data pertaining to organ support provided during the critical care stay were available for 732 patients (99.6\%) as three patients remained in units on 31/08/2020 (Table 2). Non-invasive respiratory support was received by 241 patients (32.9\%), 418 patients $(57.1 \%)$ received advanced respiratory support, and 560 patients (76.5\%) received a combination of non-invasive and invasive respiratory support. Cardiovascular support was received by $58.1 \%$ and RRT by $20.9 \%$ of patients.

The proportion surviving to critical care discharge was $70.4 \%$ with a median critical care length of stay for all patients of 6.4 days (IQR 2.4, 15.3). Those who died in critical care had a longer median length of stay than those who survived (9.5 days vs. 5.2 days). The critical care mortality rate was highest in the most socioeconomically deprived group (34.3\%) compared with all other groups (range $27.7 \%$ to $28.7 \%$ ).

The number of patients managed in critical care over time and organ support requirements are illustrated in Fig. 2. This figure demonstrates the disproportionate requirement for critical care by patients from socioeconomically deprived areas, and considerable requirement for advanced respiratory support.

Follow-up to 30 days after critical care admission was available for all patients. Overall 30-day mortality for patients with SARS-CoV-2 infection admitted to critical care was $34.8 \%$. Mortality varied by patient characteristics (Table 3, Figure S3). Age significantly impacted 30 -day mortality; mortality was $16.0 \%$ in those aged $16-49$ years compared to $56.7 \%$ in patients 70 years and older. Lower mortality rates were also observed in female compared with male patients $(27.7 \%$ vs. $37.9 \%$ ). Patients with at least one comorbidity or previous emergency hospitalisations had increased 30-day mortality. Severity of illness, as measured by requirement for organ support, was associated with 
Table 1

Baseline characteristics stratified by socioeconomic deprivation quintile. 47 records have an unknown SIMD quintile. 310 records have unknown ethnicity (Distributed in

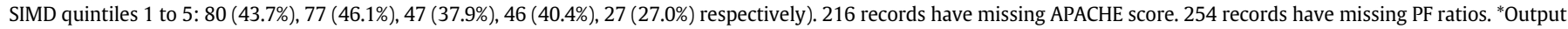
suppressed due to disclosure risk. Abbreviations: APACHE, Acute Physiology and Chronic Health Evaluation

\begin{tabular}{|c|c|c|c|c|c|c|c|}
\hline Number of patients & & All patients & 1 = Most deprived & 2 & 3 & 4 & $5=$ Least deprived \\
\hline $\begin{array}{l}\text { COVID-19 positive and admitted to } \\
\text { Critical Care }\end{array}$ & $\mathrm{n}$ & 735 & 183 & 167 & 124 & 114 & 100 \\
\hline Age on admission (years) & Median (IQR) & $61(53,68)$ & $59(50,67)$ & $62(55,68)$ & $60(54,69)$ & $61(51,71)$ & $62.5(55,70)$ \\
\hline \multirow[t]{2}{*}{ Sex } & Male & $515(70.1 \%)$ & $130(71.0 \%)$ & $111(66.5 \%)$ & $87(70.2 \%)$ & $81(71.1 \%)$ & $71(71.0 \%)$ \\
\hline & Female & $220(29.9 \%)$ & $53(29.0 \%)$ & $56(33.5 \%)$ & $37(29.8 \%)$ & $33(28.9 \%)$ & $29(29.0 \%)$ \\
\hline \multirow[t]{4}{*}{ Ethnicity } & White & $387(91.1 \%)$ & $90(87.4 \%)$ & $78(86.7 \%)$ & $75(97.4 \%)$ & $60(88.2 \%)$ & $65(97.0 \%)$ \\
\hline & Black/Caribbean/African & $7(1.6 \%)$ & * & * & $*$ & $*$ & $*$ \\
\hline & Asian & $26(6.1 \%)$ & $*$ & $*$ & $*$ & $*$ & $*$ \\
\hline & Other & $5(1.2 \%)$ & $*$ & $*$ & * & $*$ & * \\
\hline \multicolumn{8}{|l|}{ Previous health status } \\
\hline \multirow[t]{3}{*}{ Comorbidity count } & 0 & $481(65.4 \%)$ & $106(57.9 \%)$ & $113(67.7 \%)$ & $77(62.1 \%)$ & $81(71.1 \%)$ & $78(78.0 \%)$ \\
\hline & 1 & $157(21.4 \%)$ & $49(26.8 \%)$ & $28(16.8 \%)$ & $30(24.2 \%)$ & $18(15.8 \%)$ & $15(15.0 \%)$ \\
\hline & 2 plus & $97(13.2 \%)$ & $28(15.3 \%)$ & $26(15.6 \%)$ & $17(13.7 \%)$ & $15(13.2 \%)$ & $7(7.0 \%)$ \\
\hline \multirow[t]{5}{*}{ Comorbidities } & Cardiovascular Disease & $62(8.4 \%)$ & $13(7.1 \%)$ & $19(11.4 \%)$ & $9(7.3 \%)$ & $11(9.6 \%)$ & $5(5.0 \%)$ \\
\hline & Respiratory Disease & $88(12.0 \%)$ & $24(13.1 \%)$ & $22(13.2 \%)$ & $19(15.3 \%)$ & $12(10.5 \%)$ & $4(4.0 \%)$ \\
\hline & Diabetes Mellitus & $85(11.6 \%)$ & $28(15.3 \%)$ & $21(12.6 \%)$ & $14(11.3 \%)$ & $10(8.8 \%)$ & $9(9.0 \%)$ \\
\hline & Cancer & $52(7.1 \%)$ & $16(8.7 \%)$ & $9(5.4 \%)$ & $10(8.1 \%)$ & $12(10.5 \%)$ & $4(4.0 \%)$ \\
\hline & Other & $70(9.5 \%)$ & $23(12.6 \%)$ & $15(9.0 \%)$ & $15(12.1 \%)$ & $4(3.5 \%)$ & $5(5.0 \%)$ \\
\hline \multirow{3}{*}{$\begin{array}{l}\text { Emergency hospital admissions in } \\
\text { previous year }\end{array}$} & 0 & $640(87.1 \%)$ & $157(85.8 \%)$ & $143(85.6 \%)$ & $109(87.9 \%)$ & $100(87.7 \%)$ & $92(92.0 \%)$ \\
\hline & 1 & $57(7.8 \%)$ & $13(7.1 \%)$ & $13(7.8 \%)$ & $10(8.1 \%)$ & $9(7.9 \%)$ & $4(4.0 \%)$ \\
\hline & 2 plus & $38(5.2 \%)$ & $13(7.1 \%)$ & $11(6.6 \%)$ & $5(4.0 \%)$ & $5(4.4 \%)$ & $4(4.0 \%)$ \\
\hline \multicolumn{8}{|l|}{ Illness severity and organ support } \\
\hline APACHE II score & Median (IQR) & $15(12,19)$ & $15(12,19)$ & $15(12,18)$ & $16(12,20)$ & $14(11,20)$ & $15(11.75,18.25)$ \\
\hline Acute Physiology Score & Median (IQR) & $7(4,11)$ & $7(5,11)$ & $7(4,10)$ & $7.5(4,11)$ & $6(3,11)$ & $7(3,10.25)$ \\
\hline PaO2:FiO2 ratio $(\mathrm{kPa})$ & Median (IQR) & $15.4(11.1,21.3)$ & $15.2(10.6,20.8)$ & $16.4(11.6,22.9)$ & $15.1(10.6,19.6)$ & $15.0(11.1,20.9)$ & $16.8(12.8,21.9)$ \\
\hline $\begin{array}{l}\text { Time from hospital admission to ICU } \\
\text { admission (days) }\end{array}$ & Median (IQR) & $1(0,2)$ & $1(0,3)$ & $1(0,2)$ & $1(0,3)$ & $1(0,2)$ & $1(0,2)$ \\
\hline \multirow{3}{*}{$\begin{array}{l}\text { Number of organ systems supported } \\
\text { on ICU admission }\end{array}$} & 0 & $230(31.3 \%)$ & $61(33.3 \%)$ & $56(33.5 \%)$ & $31(25.0 \%)$ & $41(36.0 \%)$ & $24(24.0 \%)$ \\
\hline & 1 & $277(37.7 \%)$ & $72(39.3 \%)$ & $58(34.7 \%)$ & $45(36.3 \%)$ & $39(34.2 \%)$ & $42(42.0 \%)$ \\
\hline & 2 or more & $228(31.0 \%)$ & $50(27.3 \%)$ & $53(31.7 \%)$ & $48(38.7 \%)$ & $34(29.8 \%)$ & $34(34.0 \%)$ \\
\hline $\begin{array}{l}\text { Advanced respiratory support on } \\
\text { admission }\end{array}$ & $\mathrm{n}(\%)$ & $330(44.9 \%)$ & $90(49.2 \%)$ & $69(41.3 \%)$ & $61(49.2 \%)$ & $48(42.1 \%)$ & $49(49.0 \%)$ \\
\hline $\begin{array}{l}\text { Non-invasive respiratory support on } \\
\text { admission }\end{array}$ & $\mathrm{n}(\%)$ & $160(21.8 \%)$ & $30(16.4 \%)$ & $37(22.2 \%)$ & $28(22.6 \%)$ & $24(21.1 \%)$ & $25(25.0 \%)$ \\
\hline $\begin{array}{l}\text { Other basic respiratory support on } \\
\text { admission }\end{array}$ & $\mathrm{n}(\%)$ & $245(33.3 \%)$ & $63(34.4 \%)$ & $61(36.5 \%)$ & $35(28.2 \%)$ & $42(36.8 \%)$ & $26(26.0 \%)$ \\
\hline Cardiovascular support on admission & $\mathrm{n}(\%)$ & $239(32.5 \%)$ & $51(27.9 \%)$ & $56(33.5 \%)$ & $52(41.9 \%)$ & $34(29.8 \%)$ & $36(36.0 \%)$ \\
\hline $\begin{array}{l}\text { Renal replacement therapy on } \\
\text { admission }\end{array}$ & $\mathrm{n}(\%)$ & $10(1.4 \%)$ & $*$ & $*$ & * & * & * \\
\hline
\end{tabular}
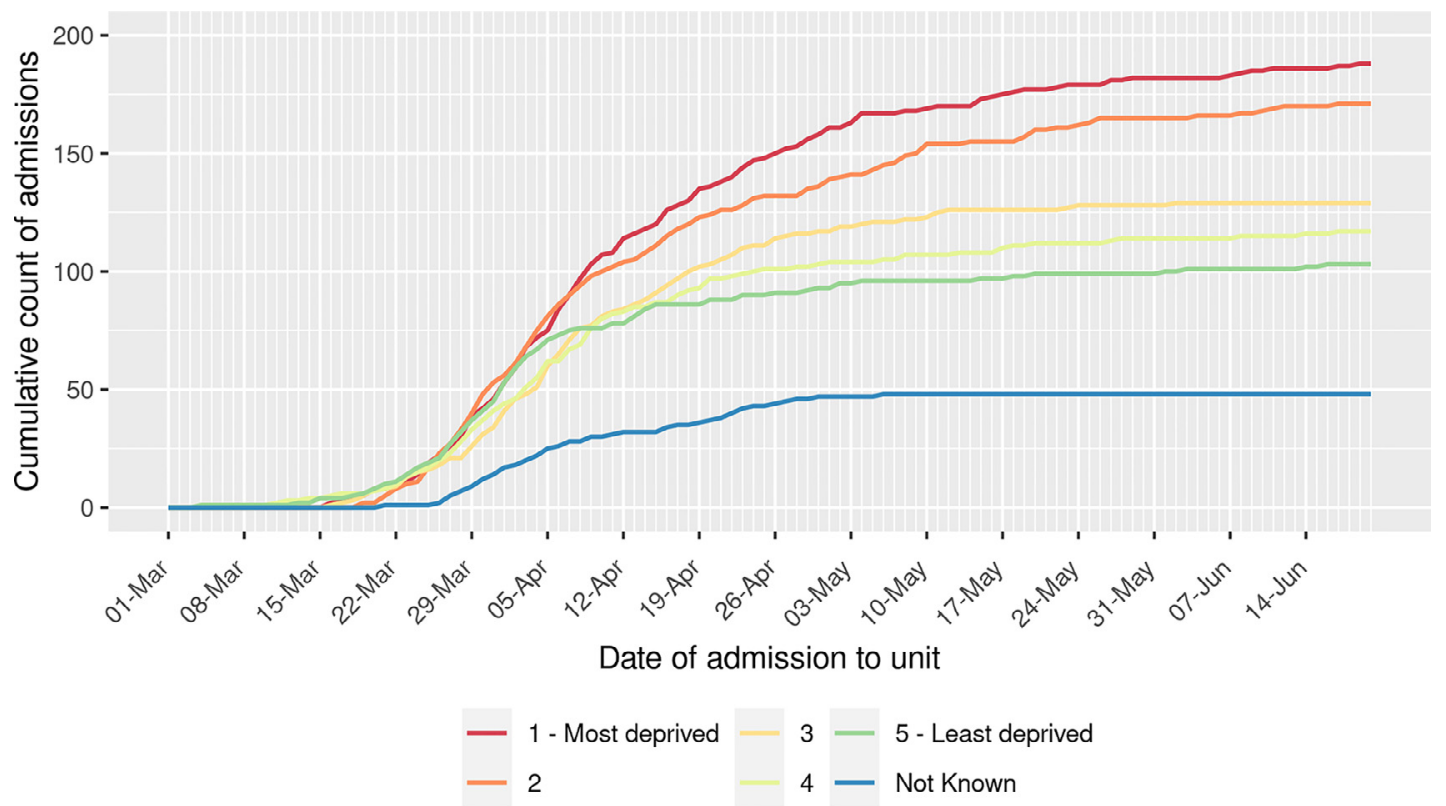

Note: In total there are 48 admissions for which SIMD information is not known.

Fig. 1. Cumulative frequency of patients with COVID-19 admitted to critical care units stratified by socioeconomic deprivation quintile. 
Table 2

Outcomes for patients who were discharged from critical care ( $\mathrm{n}=732 / 735)$, stratified by socioeconomic deprivation quintile.

\begin{tabular}{|c|c|c|c|c|c|c|c|}
\hline & & All patients discharged & 1 = Most deprived & 2 & 3 & 4 & $5=$ Least deprived \\
\hline & $\mathrm{n}$ & 732 & 181 & 166 & 124 & 115 & 100 \\
\hline \multicolumn{8}{|l|}{ Outcome on critical care discharge } \\
\hline Alive & $\mathrm{n}(\%)$ & $515(70.4 \%)$ & $119(65.7 \%)$ & $120(72.3 \%)$ & $89(71.8 \%)$ & $82(71.3 \%)$ & $72(72.0 \%)$ \\
\hline Dead & $\mathrm{n}(\%)$ & $217(29.6 \%)$ & $62(34.3 \%)$ & $46(27.7 \%)$ & $35(28.2 \%)$ & $33(28.7 \%)$ & $28(28.0 \%)$ \\
\hline \multicolumn{8}{|l|}{ Length of critical care stay (days) } \\
\hline All patients & Median (IQR) & $6.4(2.4,15.3)$ & $6.4(3,14.5)$ & $5.5(1.5,15.4)$ & $7.2(2.5,14.6)$ & $6.4(2.5,15.4)$ & $8.6(2.2,17.6)$ \\
\hline Survivors & Median (IQR) & $5.2(1.8,13.9)$ & $5.3(1.8,11.8)$ & $5.4(1.4,15.2)$ & $6.4(2.4,13.8)$ & $4.9(1.6,11.2)$ & $5.9(1.7,17)$ \\
\hline Non-survivors & Median (IQR) & $9.5(4.5,18.2)$ & $10.1(5.9,19.5)$ & $7.7(3.4,16.6)$ & $10.4(4.3,16.5)$ & $9(3.9,18.5)$ & $12.4(6.3,17.6)$ \\
\hline \multicolumn{8}{|l|}{ Organ support during stay } \\
\hline Advanced respiratory support & $\mathrm{n}(\%)$ & $418(57.1 \%)$ & $104(57.5 \%)$ & $92(55.4 \%)$ & $79(63.7 \%)$ & $64(55.7 \%)$ & $62(62.0 \%)$ \\
\hline Non-invasive respiratory support & $\mathrm{n}(\%)$ & $241(32.9 \%)$ & $51(28.2 \%)$ & $52(31.3 \%)$ & $37(29.8 \%)$ & $39(33.9 \%)$ & $43(43.0 \%)$ \\
\hline $\begin{array}{l}\text { Combined advanced/non-invasive respira- } \\
\text { tory support }\end{array}$ & $\mathrm{n}(\%)$ & $560(76.5 \%)$ & $136(75.1 \%)$ & $121(72.9 \%)$ & $100(80.6 \%)$ & $85(73.9 \%)$ & $84(84.0 \%)$ \\
\hline Cardiovascular support & $\mathrm{n}(\%)$ & $425(58.1 \%)$ & $101(55.8 \%)$ & $94(56.6 \%)$ & $83(66.9 \%)$ & $64(55.7 \%)$ & $64(64.0 \%)$ \\
\hline Renal support & $\mathrm{n}(\%)$ & $153(20.9 \%)$ & $36(19.9 \%)$ & $35(21.1 \%)$ & $28(22.6 \%)$ & $21(18.3 \%)$ & $23(23.0 \%)$ \\
\hline \multicolumn{8}{|l|}{ Duration of organ support (days) } \\
\hline Advanced respiratory support & Median (IQR) & $13(7,22.8)$ & $13(8,22)$ & $12.5(6,22.2)$ & $12(6,22)$ & $11(6,21.8)$ & $14(10,21)$ \\
\hline Non-invasive respiratory support & Median (IQR) & $3(1,5)$ & $3(2,6)$ & $2(1,4.2)$ & $3(1,5)$ & $3(2,5)$ & $2(1,5)$ \\
\hline $\begin{array}{l}\text { Combined advanced/non-invasive respira- } \\
\text { tory support }\end{array}$ & Median (IQR) & $10(5,20)$ & $10(6,19.2)$ & $8(4,20)$ & $9.5(4,18.5)$ & $10(5,18)$ & $12.5(4.8,20.2)$ \\
\hline Cardiovascular support & Median (IQR) & $6(3,10)$ & $6(4,10)$ & $7(4,10)$ & $5(3,9)$ & $6(3,10)$ & $6.5(3,11)$ \\
\hline Renal support & Median (IQR) & $10(4,17)$ & $11.5(4.8,16)$ & $7(2,15.5)$ & $10.5(4.5,15)$ & $10(4,19)$ & $11(4,20)$ \\
\hline
\end{tabular}

higher mortality rates for each mode of support, and mortality increased with increasing total number of organs supported.

\subsection{Association between socioeconomic deprivation and 30-day mortality}

Crude mortality measured at 30-days after critical care admission was non-significantly higher in patients residing in the most socioeconomically deprived quintile compared with those from the least socioeconomically deprived quintile (42.6\% vs $34.0 \%$; OR 1.44 , $95 \% \mathrm{CI} 0.87,2.39, p=0.157$ ) (Table 4). After adjusting for age, sex and ethnicity, mortality was significantly higher in patients from the most socioeconomically deprived quintile (OR 1.97, 95\%CI 1.13, 3.41, $p=0.016$ ). Following further adjustment for comorbidities, previous emergency admissions and APS, this increase in mortality persisted (OR 1.78, 95\%CI 1.01, 3.15, $p=0.046$ ). Similar results were found in the
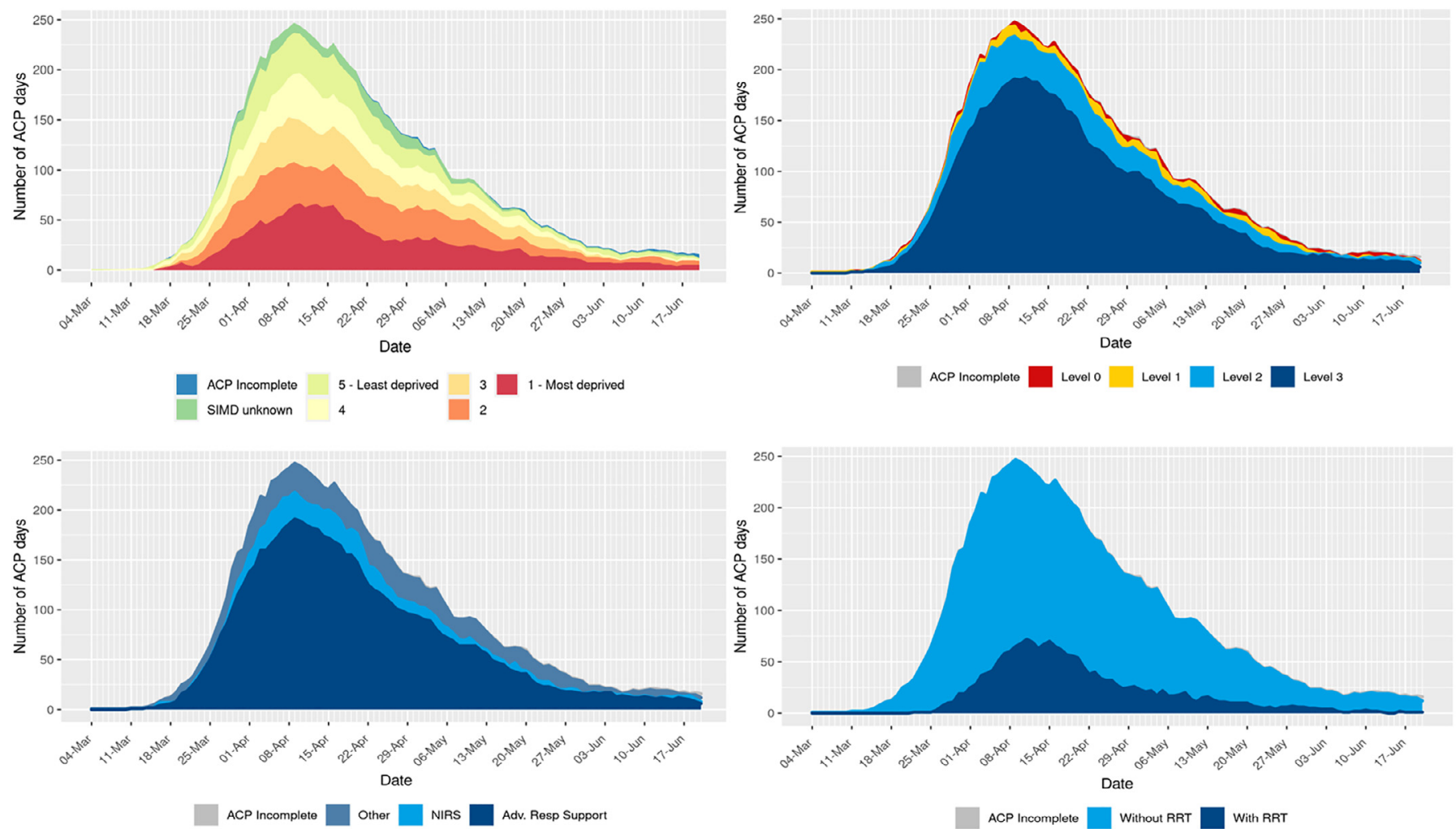

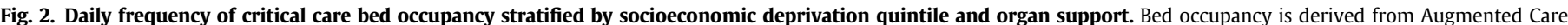

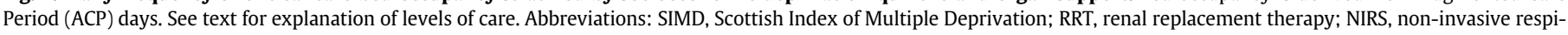
ratory support; Adv Res, advanced respiratory. 
Table 3

30-day mortality stratified by baseline characteristics ( $n=735)$. Abbreviations: SIMD, Scottish Index of Multiple Deprivation.

\begin{tabular}{|c|c|c|}
\hline & & 30 day mortality $\mathrm{n}(\%)$ \\
\hline Overall 30-day mortality & & $256(34.8 \%)$ \\
\hline \multirow{4}{*}{$\begin{array}{l}\text { Age on admission } \\
\text { (years) }\end{array}$} & $16-49$ & $21(16.0 \%)$ \\
\hline & $50-59$ & $54(26.2 \%)$ \\
\hline & $60-69$ & $84(37.0 \%)$ \\
\hline & 70 or more & $97(56.7 \%)$ \\
\hline \multirow[t]{2}{*}{ Sex } & Male & $195(37.9 \%)$ \\
\hline & Female & $61(27.7 \%)$ \\
\hline \multirow[t]{3}{*}{ Ethnicity } & White & $156(40.3 \%)$ \\
\hline & $\begin{array}{l}\text { Black/Caribbean/ Afri- } \\
\text { can/Asian/Other }\end{array}$ & $14(36.8 \%)$ \\
\hline & Missing & $86(27.7 \%)$ \\
\hline \multirow[t]{5}{*}{ SIMD quintile } & 1 - Most deprived & $78(42.6 \%)$ \\
\hline & 2 & $52(31.1 \%)$ \\
\hline & 3 & $40(32.3 \%)$ \\
\hline & 4 & $37(32.5 \%)$ \\
\hline & 5 - least deprived & $34(34.0 \%)$ \\
\hline \multicolumn{3}{|l|}{ Previous health status } \\
\hline \multirow[t]{3}{*}{ Comorbidity count } & 0 & $143(29.7 \%)$ \\
\hline & 1 & $71(45.2 \%)$ \\
\hline & 2 or more & $42(43.3 \%)$ \\
\hline \multirow{2}{*}{$\begin{array}{l}\text { Emergency hospital } \\
\text { admissions in previ- } \\
\text { ous year }\end{array}$} & 0 & $212(33.1 \%)$ \\
\hline & 1 or more & $44(46.3 \%)$ \\
\hline \multicolumn{3}{|l|}{$\begin{array}{l}\text { Illness severity and } \\
\text { organ support }\end{array}$} \\
\hline \multirow{4}{*}{$\begin{array}{l}\text { Acute Physiology Score } \\
\text { (tertiles) }\end{array}$} & $0-4$ & $43(27.2 \%)$ \\
\hline & $5-8$ & $50(30.5 \%)$ \\
\hline & 9 or more & $98(49.8 \%)$ \\
\hline & Missing & $65(30.1 \%)$ \\
\hline \multirow{4}{*}{$\begin{array}{l}\text { Number of organ sys- } \\
\text { tems supported on } \\
\text { ICU admission }\end{array}$} & 0 & $25(15.8 \%)$ \\
\hline & 1 & $45(28.7 \%)$ \\
\hline & 2 & $106(39.3 \%)$ \\
\hline & 3 & $80(53.3 \%)$ \\
\hline \multirow{2}{*}{$\begin{array}{l}\text { Advanced respiratory } \\
\text { support on admission }\end{array}$} & No & $77(24.5 \%)$ \\
\hline & Yes & $179(42.5 \%)$ \\
\hline \multirow{2}{*}{$\begin{array}{l}\text { Non-invasive respira- } \\
\text { tory support on } \\
\text { admission }\end{array}$} & No & $185(37.5 \%)$ \\
\hline & Yes & $71(29.3 \%)$ \\
\hline \multirow{2}{*}{$\begin{array}{l}\text { Other basic respiratory } \\
\text { support }\end{array}$} & No & $173(82.8 \%)$ \\
\hline & Yes & $83(15.8 \%)$ \\
\hline \multirow{2}{*}{$\begin{array}{l}\text { Cardiovascular support } \\
\text { on admission }\end{array}$} & No & $71(23.2 \%)$ \\
\hline & Yes & $185(43.1 \%)$ \\
\hline \multirow{2}{*}{$\begin{array}{l}\text { Renal replacement ther- } \\
\text { apy on admission }\end{array}$} & No & $172(29.7 \%)$ \\
\hline & Yes & $84(54.2 \%)$ \\
\hline
\end{tabular}

subgroup of mechanically ventilated patients (fully adjusted model OR 2.23, 95\%CI 1.10, 4.51, $p=0.010$ ) (Table S3).

\subsection{ICU capacity}

Nationally, baseline ICU capacity was exceeded for 25 days, with the majority of the workload due to patients with confirmed COVID19 (Fig. 3). Maximum capacity peaked at $145 \%$ of baseline capacity.

ICUs serving areas of higher socioeconomic deprivation spent a greater total amount of time over their baseline capacity (34 days), than those in areas of less socioeconomic deprivation (14 days) (Fig. 3). Units in the most socioeconomically deprived areas also operated over capacity for a more prolonged period (33 days), whereas those in the least socioeconomically deprived areas experienced several short episodes of being over capacity, with a maximum of 7 consecutive days over capacity.

As well as time above baseline capacity, health boards serving more socioeconomically deprived populations experienced a higher peak over capacity with peaks of $136 \%, 123 \%$ and $165 \%$ of percentage baseline capacity for the low, medium and high socioeconomic deprivation groups respectively.

\section{Discussion}

This complete national cohort study has demonstrated that those living in the most socioeconomically deprived areas are more likely to be admitted to, and have poorer outcomes after, critical care. Further, it has uniquely shown that units which provided care in areas of higher socioeconomic deprivation spent a greater amount of time above baseline bed capacity and had a larger magnitude of change in relation to bed expansion.

There are a variety of mechanisms which may be driving the increased ICU admission rates and mortality seen in patients from socioeconomically deprived areas. For example, the financial necessity to continue working or the nature of employment may increase the exposure to the virus in those living in socioeconomically deprived areas [16]. Public transport may pose a significant risk factor for the spread of SARS-CoV-2 and thus, workers who are unable to work from home may potentially have this additional exposure risk [17].

The association between poor housing and health could be further driving the observed inequalities. Those living in areas of higher socioeconomic deprivation are more likely to live in crowded accommodation which can lead to a higher risk of exposure and infecting dose [18]. In addition, areas of socioeconomic deprivation have a higher proportion of people who suffer from the non-communicable health conditions which increase the risk of severe COVID-19 disease, such as hypertension, obesity, diabetes and heart disease [19]. These factors may lead to more severe disease and an increased necessity for ICU admission or even a higher risk of death.

In Scotland, urban living, income deprivation and household overcrowding have already been linked to increased COVID-19 mortality [20]. This effect was more pronounced than that demonstrated for non-COVID mortality during the same time period, indicating that COVID-19 disproportionally impacts upon those from deprived areas. This is consistent with the findings from our study which found both a higher rate of ICU admission and adjusted mortality for patients from areas of socioeconomic deprivation.

\subsection{Comparison to known literature}

Our study builds on recent studies reporting the association between socioeconomic deprivation and increased mortality from COVID-19 [9,21,22]. To our knowledge, this is the first published study to describe the impact of socioeconomic deprivation on ICU bed capacity at a national level. The association between socioeconomic status and healthcare usage in the non-COVID population has been previously described. In a review of hospital admissions in England, although the rates of elective admission were similar across socioeconomic deprivation groupings, emergency admissions increased with increasing level of socioeconomic deprivation [23]. Modelling work in the London region has highlighted a similar increase in critical care utilisation associated with increased socioeconomic deprivation, with varying clinical presentations seen in different societal groups [24]. Despite the increase in healthcare utilisation, socioeconomic deprivation has been found to be only a weak predictor of critical care mortality in non-COVID-19 patients within the Scottish critical care setting [25]. This is in contrast to the increased mortality that we have observed in the COVID-19 population from the most socioeconomically deprived areas. 
Table 4

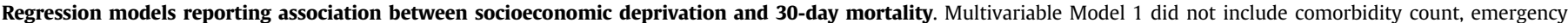

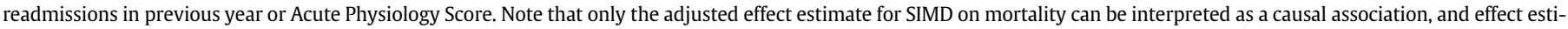

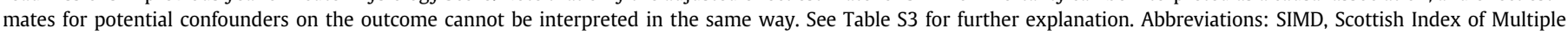
Deprivation.

\begin{tabular}{|c|c|c|c|c|}
\hline & & Univariable & Multivariable Model 1 & Multivariable Model 2 \\
\hline \multirow[t]{5}{*}{ SIMD quintile } & 5 - Least deprived & 1 (ref) & 1 (ref) & 1 (ref) \\
\hline & 4 & $0.93(0.53,1.65) \mathrm{p}=0.811$ & $1.01(0.55,1.86) \mathrm{p}=0.981$ & $0.98(0.52,1.84) \mathrm{p}=0.951$ \\
\hline & 3 & $0.92(0.53,1.62) \mathrm{p}=0.783$ & $1.07(0.59,1.94) \mathrm{p}=0.823$ & $0.93(0.50,1.71) \mathrm{p}=0.808$ \\
\hline & 2 & $0.88(0.52,1.49) \mathrm{p}=0.628$ & $1.03(0.58,1.80) \mathrm{p}=0.930$ & $0.96(0.54,1.72) \mathrm{p}=0.895$ \\
\hline & 1 - Most deprived & $1.44(0.87,2.39) \mathrm{p}=0.157$ & $1.97(1.13,3.41) \mathrm{p}=0.016$ & $1.78(1.01,3.15) \mathrm{p}=0.046$ \\
\hline Age on admission & Per 1 year increase & $1.06(1.05,1.08) \mathrm{p}<0.001$ & $1.07(1.05,1.09) \mathrm{p}<0.001$ & $1.07(1.05,1.09) \mathrm{p}<0.001$ \\
\hline \multirow[t]{2}{*}{ Sex } & Male & 1 (ref) & 1 (ref) & 1 (ref) \\
\hline & Female & $0.63(0.44,0.89) \mathrm{p}=0.010$ & $0.70(0.48,1.02) \mathrm{p}=0.066$ & $0.70(0.47,1.03) \mathrm{p}=0.073$ \\
\hline \multirow[t]{3}{*}{ Ethnicity } & White & 1 (ref) & 1 (ref) & \\
\hline & Black/Caribbean/ African/Asian/Other & $0.94(0.47,1.88) \mathrm{p}=0.853$ & $1.41(0.66,3.00) \mathrm{p}=0.375$ & $1.42(0.65,3.12) \mathrm{p}=0.376$ \\
\hline & Missing & $0.63(0.45,0.87) \mathrm{p}=0.006$ & $0.51(0.35,0.73) \mathrm{p}<0.001$ & $0.61(0.39,0.95) \mathrm{p}=0.029$ \\
\hline \multirow[t]{3}{*}{ Comorbidity count } & 0 & 1 (ref) & - & 1 (ref) \\
\hline & 1 & $1.88(1.27,2.77) \mathrm{p}=0.001$ & - & $1.51(0.97,2.33) \mathrm{p}=0.065$ \\
\hline & 2 or more & $1.73(1.10,2.74) \mathrm{p}=0.018$ & - & $1.31(0.75,2.32) \mathrm{p}=0.344$ \\
\hline \multirow[t]{2}{*}{ Emergency hospital admissions in previous year } & 0 & 1 (ref) & - & 1 (ref) \\
\hline & 1 or more & $1.69(1.08,2.67) \mathrm{p}=0.023$ & - & $1.54(0.86,2.76) \mathrm{p}=0.147$ \\
\hline \multirow[t]{4}{*}{ Acute Physiology Score } & Tertile $1(0-4)$ & 1 (ref) & - & 1 (ref) \\
\hline & Tertile $2(5-8)$ & $1.19(0.73,1.95) \mathrm{p}=0.485$ & - & $1.22(0.72,2.07) \mathrm{p}=0.454$ \\
\hline & Tertile 3 (9-28) & $2.65(1.67,4.19) \mathrm{p}<0.001$ & - & $2.43(1.47,4.03) \mathrm{p}=0.001$ \\
\hline & Missing & $1.22(0.76,1.95) \mathrm{p}=0.405$ & - & $1.05(0.58,1.91) \mathrm{p}=0.866$ \\
\hline
\end{tabular}

Although socioeconomic deprivation is known to be associated with increased healthcare utilisation, it is unknown how well the healthcare resource capacity matches this potential need. From our study, we have demonstrated that increased periods of overcapacity were experienced in centres serving Scotland's most socioeconomically deprived communities. On review of performance at other times of prolonged stress, such as during nursing strikes, these periods are associated with an increase in mortality and other quality indicators such as readmission [23]. Knowing this may assist with future decisions regarding both human and equipment resource allocation when planning for future pandemics.

\subsection{Strengths and limitations}

Our study has a number of strengths. We were able to define COVID-19 status for patients admitted to critical care using laboratory-confirmed PCR testing. The SICSAG database was adapted in real-time during the pandemic to respond to rapidly changing service configurations so that it included critically ill patients ventilated in other areas of the hospital, such as theatre recovery. We are therefore confident that we had complete capture of all COVID-19 patients receiving mechanical ventilation in Scotland. The use of national, linked databases allowed us to ascertain pre-morbid health status, including COVID-19 related conditions such as diabetes mellitus and severe renal disease, and outcomes for all patients with no loss to follow-up. In addition, we were also able to report ICU activity relative to baseline funded ICU capacity.

A number of limitations impact on our study findings. Whilst the study reported the impact of COVID-19 at a country level, precision of estimates was affected by sample size and outcome frequency. SIMD is an area-based rather than individual-level measure of socioeconomic deprivation, and measurement error may therefore limit its inference at an individual patient level. It is possible that some of the differences between outcomes for patients from areas of socioeconomic deprivation are attributable to selection bias. Had these patients been subject to a higher threshold of hospital or ICU admission, they might represent a "sicker" population. However, comparison of severity of illness measures such as APACHE II score and PF ratio were similar across deprivation groups suggesting a similar burden of acute illness. We were unable to record less severe comorbidities that are known to be associated with COVID-19 disease outcomes, such as hypertension or obesity. This may lead to residual confounding affecting the association between socioeconomic deprivation and mortality. Non-invasive respiratory support was provided in some hospitals outside of designated critical care areas. For this reason, we were unable to capture all non-invasive respiratory support in the country. Whilst missing data were present for only a small proportion of patients for socioeconomic deprivation status, a greater proportion of data were missing for ethnicity and APS. We included these as missing indicator variables in multivariable models, which may bias exposure-outcome associations. However, in the subgroup analysis of patients receiving mechanical ventilation in whom the proportion of missing data was lower, we reported a similar association between socioeconomic deprivation and mortality.

\subsection{Implications for clinicians, policymakers and future research}

These findings are important for planning of critical care services in a future wave. A per capita approach to expanding health care services may not be the best strategy to meet future demand. Given that critical care units serving socioeconomically deprived areas experienced a higher peak of demand for critical care and for a more prolonged period of time, a more targeted approach to additional resource should be considered.

The cause of increased mortality in people with COVID-19 living in socioeconomically deprived settings requires further investigation. Our sequential approach to modelling indicated that the increase in mortality was not mediated through comorbidity, previous healthcare use or severity of illness on presentation. Access to prospectively collected datasets which record additional characteristics, such as less severe comorbidities, features of late disease presentation (e.g. time from symptom onset to hospital presentation) may help unpick this further.

In this complete national cohort study of patients with COVID-19 admitted to critical care units, those living in areas in the most socioeconomically deprived quintile of Scotland had a higher chance of critical care admission and a higher adjusted 30-day mortality. Health boards with higher levels of socioeconomic deprivation had both higher peak critical care occupancy and longer duration of occupancy over normal maximum capacity. 

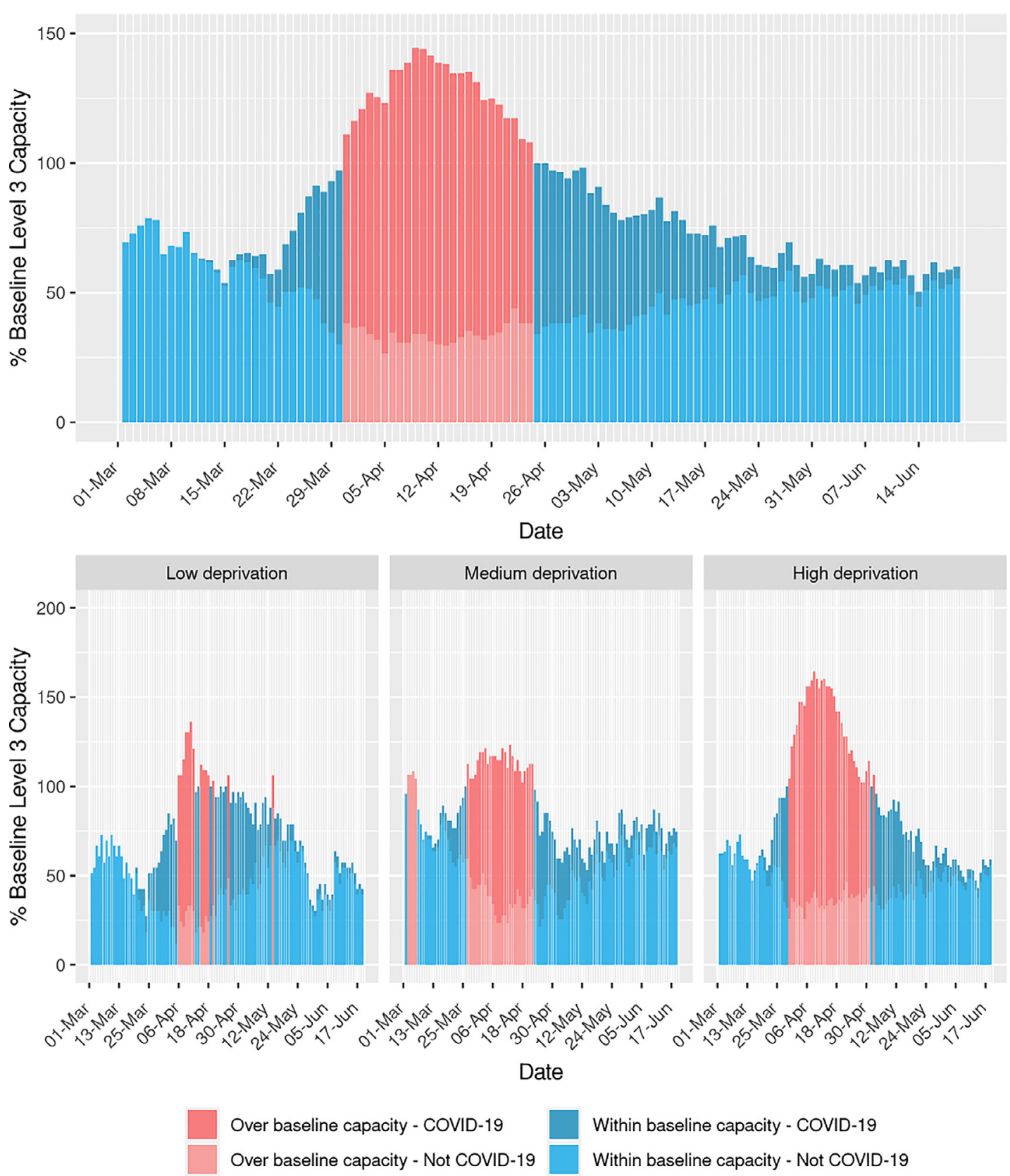

Over baseline capacity - Not COVID-19

Within baseline capacity - COVID-19

Within baseline capacity - Not COVID-19

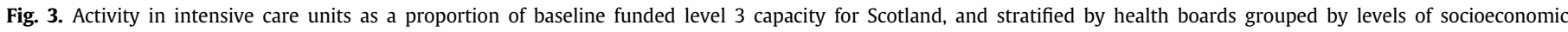
deprivation.

\section{Authors' contributions and transparency statement}

NL affirms that the manuscript is an honest, accurate, and transparent account of the study being reported; that no important aspects of the study have been omitted; and that any discrepancies from the study as planned have been explained. NL, $\mathrm{JM}, \mathrm{NS}, \mathrm{MB}, \mathrm{CK}$ and KP contributed to conception and design of the work. All authors contributed to data acquisition or analysis. All authors contributed to interpretation of data for the work. NL, JM, NS, MB, CK and KP drafted the work. All authors revised it critically for important intellectual content. All authors gave final approval of the version to be published. All authors agree to be accountable for all aspects of the work in ensuring that questions related to the accuracy or integrity of any part of the work are appropriately investigated and resolved.

\section{Declaration of Competing Interests}

All authors declare: no support from any organisation for the submitted work; no financial relationships with any organisations that might have an interest in the submitted work in the previous three years; NL is Director of Research, Intensive Care Society; JM is funded by a THIS.Institute (University of Cambridge) Research Fellowship (PD-2019-02-16). The funder had no role in the study design; in the collection, analysis and interpretation of the data; in the writing of the report; and in the decision to submit the paper for publication.

\section{Acknowledgments}

We thank all the clinicians in the Scottish ICUs who contributed data to the Scottish Intensive Care Society Audit Group registry (SICSAG). 


\section{Data sharing statement}

Since analyses involved data on unconsented participants, we are unable to share individual level data.

\section{Ethical/information governance approval}

The Scottish Intensive Care Society Audit Group in Public Health Scotland has a legislative remit to process personal data in relation to public health. Linkage to additional datasets was approved following scrutiny by the Public Benefit and Privacy Panel for Health and Social Care (ref 1920-0093). Access and use of the data for the purpose of this work were approved following a Public Health Scotland information governance review of linking additional internal datasets to identify patients with COVID-19. Only analysts working in Public Health Scotland had access to the linked patient data which could only be accessed via an NHS secure network.

\section{Supplementary materials}

Supplementary material associated with this article can be found, in the online version, at doi:10.1016/j.lanepe.2020.100005.

\section{References}

[1] Docherty AB, Harrison EM, Green AG. Features of 20133 UK patients in hospital with covid-19 using the ISARIC WHO clinical characterisation protocol: prospective observational cohort study. Br Med J 2020;369:m1985.

[2] UK Government (2020) Coronavirus (COVID-19) in the UK. Accessed 7th of November 2020 https://coronavirus.data.gov.uk/details/deaths.

[3] Richardson S, Hirsch JS, Narasimhan DO, et al. Presenting characteristic, co-morbidities and outcomes among 5700 patients hospitalized with COVID-19 in the New York City area. J Am Med Ass 2020;323(20):2052-9.

[4] Karaglannidis C, Mostert C, Hentschker C, et al. Case characteristics, resource use and outcomes of 10021 patients with COVID-19 admitted to 920 German hospitals: an observational study. Lancet Respir Med 2020 published early online: Published Online July 28, 2020 https://doi.org/10.1016/S2213-2600(20)30316-7.

[5] Intensive Care National Audit and Research Centre (2020) ICNARC report on COVID-19 in critical care. 31st of July 2020. Accessed 7th of November: https:/ www.icnarc.org/Our-Audit/Audits/Cmp/Reports

[6] Williamson EJ, Walker AJ, Bhaskaran K, et al. Factors associated with COVID-19 related death using OpenSAFELY. Nature 2020;584:430-6

[7] Wendel Garcia, PD. Fumeaux, T. Guerci, P. et al. Prognostic factors associated with mortality risk and disease progression in 639 critically ill patients with COVID-19 in Europe: Initial report of the international RISC-19-ICU prospective observational cohort. EClinicalMedicine, Volume 25, 100449
[8] Office for National Statistics (2020) Death involving COVID-19 by local area and socioeconomic deprivation: deaths occurring between 1 March and 17 April 2020. Accessed 4th of August 2020: https://www.ons.gov.uk/peoplepopulationandcommunity/birthsdeathsandmarriages/deaths/bulletins/deathsinvolvingcovid19bylocalareasanddeprivation/deathsoccurringbetween 1 marchand 17 april

[9] Wadhera RK, Wadhera P, Gaba P, et al. Variation in COVID-19 hospitalisations and deaths across New York City boroughs. J Am Med Ass 2020;323(21):2192-5.

[10] SICSAG (2019) Scottish Intensive Care Society Audit Group Annual Report: Audit of Intensive Care Units in Scotland 2019 Reporting on 2018. Accessed 1st of September 2020 via: https://www.sicsag.scot.nhs.uk/publications/_docs/2019-0813-SICSAG-report.pdf?1

[11] Scottish Government (2020) Scottish Index of Multiple Deprivation 2020 Accessed 4th of August 2020: https://www.gov.scot/collections/scottish-indexof-multiple-deprivation-2020

[12] National Records of Scotland. (2018) Scotland's Census: Ethnic group. Accessed 7th of November 2020: https://www.scotlandscensus.gov.uk/variables-classification/ethnic-group

[13] Lone NI, Gillies MA, Haddow C, et al. Five-year mortality and hospital costs associated with surviving intensive care. Am J Respir Crit Care Med 2016;194(2):198208.

[14] SICSAG (2020) Scottish Intensive Care Society Audit Group report on COVID-19 as at 20 June 2020. Accessed 1st of September 2020 via: https://beta.isdscotland. org/find-publications-and-data/population-health/covid-19/scottish-intensivecare-society-audit-group-report-on-covid-19/

[15] R Development Core Team. R: a language and environment for statistical computing. Vienna, Austria: R Foundation for Statistical Computing; 2018 https://www. R-project.org/.

[16] Niedzwiedz CL, O’Donnell CA, Dinesh Jani B, et al. Ethnic and socioeconomic difference in SARS-CoV-2 infection: prospective cohort study using UK Biobank. BMC Medicine 2020;19:160.

[17] Hamidi S, Sabouri S, Ewing R. Does density aggravate the COVID-19 pandemic? J Am Plann Assoc 2020 https://doi.org/10.1080/01944363.2020.1777891.

[18] Gibson M, Petticrew M, Bambra C et al. Housing and health inequalities: a synthesis of systematic reviews of interventions aimed at different pathways linking housing and health. Health Place 2011;17(1):175-84.

[19] Bambra C, Riordan R, Ford J, et al. The COVID-19 pandemic and health inequalities. J Epidemiol Community Health 2020. doi: 10.1136/jech-2020-214401.

[20] Public Health Scotland (2020). What explains the spatial variation in COVID-19 mortality across Scotland? Accessed 7th of November 2020; https://www.publichealthscotland.scot/media/2814/spatial-variation-in-covid-19-mortality-inscotland-english-september2020.pdf

[21] Baumer, T. Phillips, E. Dhadda, A. et al (2020) Insights into the Epidemiology of the First Wave of COVID-19 ICU Admissions in South Wales; the Interplay between Ethnicity and Deprivation. (doi:10.20944/PREPRINTS202006.0029.V1)

[22] Doidge JC, Mouncey PR, Thomas K, et al. Trends in intensive care for patients with COVID-19 in England, Wales and Northern Ireland. Preprints 2020. doi: 10.20944/preprints202008.0267.

[23] Propper C, Stoye G, Zaranko B. The wider impacts of the coronavirus pandemic on the NHS. Fisc Stud 2020;41(2):345-56. doi: 10.1111/1475-5890.12227.

[24] Beeknoo N, Jones R. Locating areas with high use of critical care. Br J Healthc Manag 2016;22(11):551-60.

[25] Docking RI, Mackay A, Williams C, et al. Comorbidity and intensive care outcome a multivariable analysis. J Intens Care Soc 2014;15(3):205-12. 